\title{
Screw Layout Optimization to Solve Fatigue Fracture of Femoral Ti Alloy Metal Plate
}

\author{
XIE Tian ${ }^{1, a}$ and LUO Yabo ${ }^{1, b, *}$ \\ ${ }^{1}$ Mechanical and Electrical Engineering, Wuhan University of Technology, Wuhan, China \\ a2510113987@qq.com, bluoyabo1973@163.com
}

\begin{abstract}
After femoral shaft fractures, metal plates can be implanted to help its recovery. However, the main problem is that a bone fracture plate could crack or fail in the process of recovery, which cause a secondary damage to the patient. The stress concentration caused by the screw layout of the implanted plate is one of the main reasons for the fracture or failure. Since different screw layout solutions lead to different features of stress concentration, taking the femoral straight $\mathrm{Ti}$ alloy metal plate as the object, this research employed the optimization theory and the finite element analysis method to optimize the screw layout. Finally the optimal solution is obtained, which can improve fatigue strength of the fixation system and reduce the failure probability of the system, avoiding the secondary damage to the patient.
\end{abstract}

\section{Introduction}

One of the most common fractures is comminuted fracture of femoral shaft supported the main force of human lower body and difficult to recover. Most femur bone plates are locked, and which will continue to be a small probability of failure after implantation. Clinical study data suggests that the failures of bone plate are usually divided into three categories [1]:

Fracture of plates: Local stress concentration of plate can lead to fatigue fracture, of which most occurs in compression screw holes as Fig. 1(a).

Remove of locking screw: The mating threaded of screw and plate leads to riveting force. The thread failure will result in overall failure of internal fixation system. See as Fig. 1(b).

Fracture of screws: the screws fracture is usually at the joint of screw shank and head, as Fig. 1(c). The screw changing shape greatly weakens the strength and leads to stress concentration.

\footnotetext{
* Corresponding author:luoyabo1973@163.com
} 

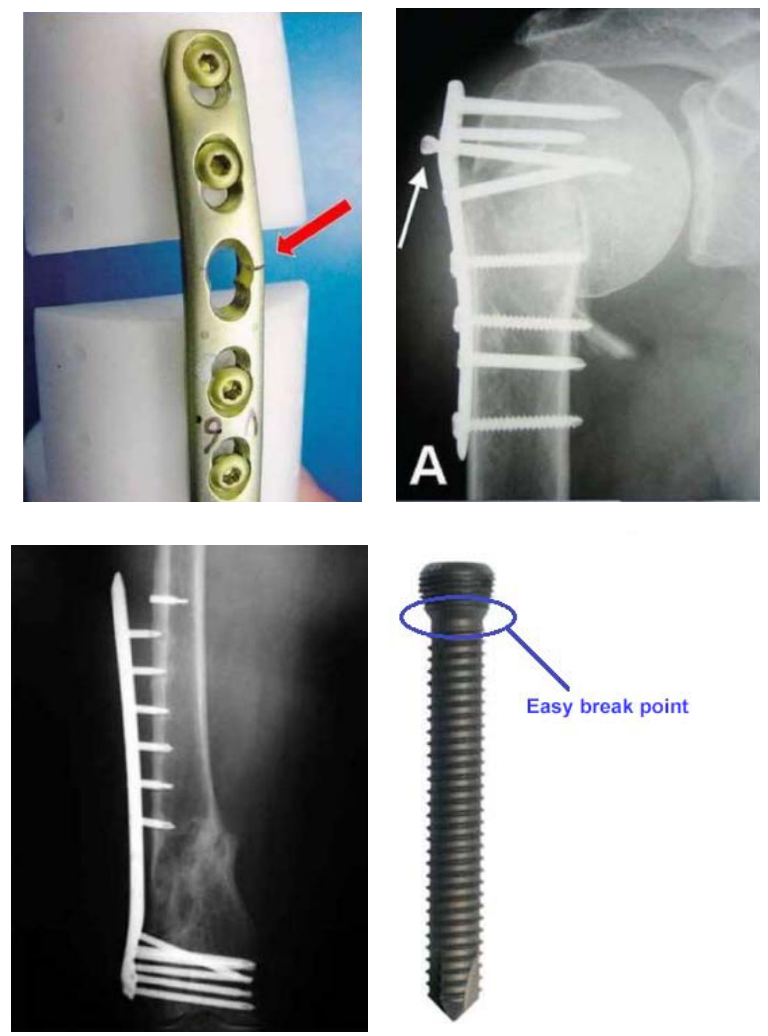

Fig. 1(a)

Fig. 1(b)

Fig. 1(c)

Fig. 1 The basic features of the fatigue fracture of femoral Ti alloy metal plate

Through the mechanical model of implanted plates, this paper aims to analyze the mechanical properties of metal plates to obtain the optimal screws layout. 8-hole femur straight plate is chosen and four plans will be chosen based on existed screw layout principles [2] and medical theory. Finite element analysis software is used to analyze that plans. Five indicators are selected: the maximum axial displacement of the proximal cross-section; the maximum stress of plate and fracture segment; the maximum stress of screw; and the maximum shear stress of screw.

\section{The Characteristics and Principles of Internal Fixation System}

\subsection{Force Status of the Femoral Shaft}

Bending long tubular structure of any material will generate tension side and pressure side when loading axially.

Due to the strong compressive performance and relatively weak tension performance of bone tissue, the plate should be placed on the outside or posterolateral of long tubular fracture. In that case, the load plate will replace cracked femur to sustain tension.

Fracture patients should not do strenuous exercise after operations. As is known when an adult weighed $70 \mathrm{~kg}$ walking slowly, the strength on femur is as shown in single leg loading. Where joint strength transmitted by femur $\mathrm{J}=1588 \mathrm{~N}$, gluteus muscle group strength $\mathrm{N}=1039 \mathrm{~N}$, the muscle strength $\mathrm{R}=169 \mathrm{~N}$. The features of strength direction is 
shown in literature [3], where $\theta=29.5^{\circ}, \varphi=24.4^{\circ}, \alpha=135^{\circ}$, the direction of $\mathrm{R}$ is vertically downward.

\subsection{Principle Used in Locking Plate}

Based on versatility, this paper determines external articular fracture model of AO/OTA $33 \mathrm{~A} 3$ external bones comminuted type is to be used [4]. Cut $1 \mathrm{~cm}$ from distal femur, and $3 \mathrm{~cm}$ medial bone defect. Set simplified model as shown in Fig. 2 through three-dimensional software UG10.0, in which, the femur diameter is $30 \mathrm{~mm}$ and the length is $250 \mathrm{~mm}$.

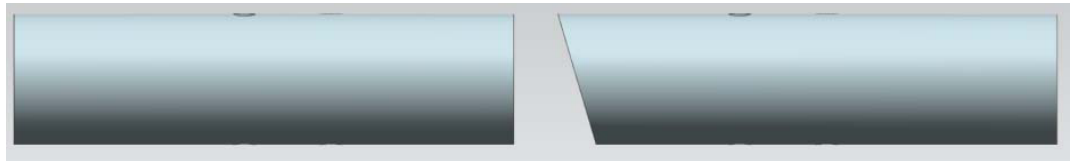

Fig. 2 The simplified model

Locking compression plate can choose appropriate fixed principle according to different fracture types. Bridge principles should be considered when femoral shaft comminuted. Elastic fixation is called perfectly elastic fixed under bridge principle. Elastic fixed model shown as Fig. 3 allows mutual displacement between blocks when bearing stress, external stress can only make plate deform reversibly. After removing the stress, the fracture fragments can be restored to previous position.

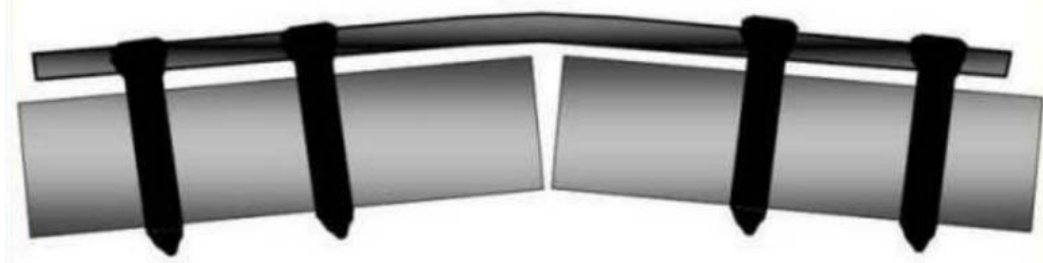

Fig. 3 Elastic fixed model

In addition, there is a gap between bone surface and the plate, but the gap between LCP(Locking Compression Plate) and bone surface is too large ( $>5 \mathrm{~mm}$ ) or too small will reduce the axial strength and torsional rigidity of structure, and the effect caused by the latter one is on more obvious than the former. Based on clinical experience, the gap is usually about $2 \mathrm{~mm}$, on the one hand, it can ensure the blood supply of bone, and on the other hand, it can directly form callus around fractures and under the plate.

\subsection{Select the Screw Plate Layout Programs}

Based on femoral shaft fracture types and fixed principles mentioned above, 8 holes femur straight plate is chosen, the length is $174 \mathrm{~mm}$. The diameter of screw is $5 \mathrm{~mm}$, and the length is $44 \mathrm{~mm}$, which is bicortical locking screw. It should be noted that, in the establishment of the locking plate and screw models by UG10.0, the threaded hole on plate and screw is simplified in order to facilitate the calculation of ANSYS analysis, and grooves, fillets and other features are omitted. These will not cause significant impact on the analysis of the results, but if not do so, which will negative the computing speed and waste resources. Its model is shown as Fig. 4 and Fig. 5. 


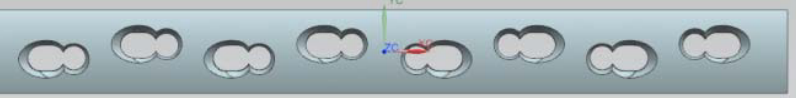

Fig. 4 Femur straight plate

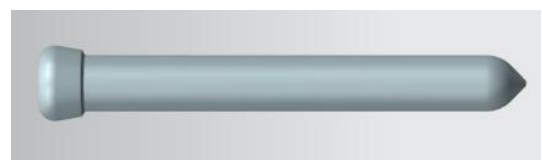

Fig. 5 Locking screw

For complex bridge connections, there are some basic principles for screw layout [5]:

The position for screw holes should be left empty at fracture area, but for comminuted, screws should get close to fracture as much as possible to reduce supported strength.

Choose a suitable length of plate, screw type, screws numbers to take a reasonable fixation methods, namely higher span ratio ( the ratio of plate length and fracture zone length $\geq 2 \sim 3$ ), and lower screw density ( the ratio of screwed screws number and all screw holes on plate $\leq 0.5 \sim 0.4$ ).

For bridge connection plates, the basic principle of screw is "long steel, less screws", and both ends of the plate need to be implanted screws.

Number the plates. According to actual situation, screw layout is as Fig. 6:

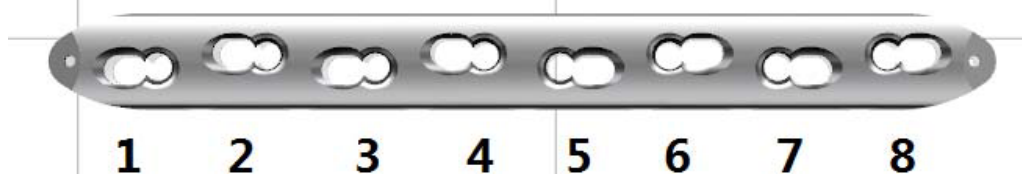

Fig. 6 Screw layout

Table 1 Screw Layout

\begin{tabular}{|c|c|c|c|c|c|c|c|}
\hline$[1]$ & {$[2]$} & {$[3]$} & {$[4]$} & {$[5]$} & {$[6]$} & {$[7]$} & {$[8]$} \\
\hline$[$ Plan 1] & {$[\mathrm{LS}]$} & {$[\mathrm{LS}]$} & & {$[$ Fracture Zone $]$} & & {$[\mathrm{LS}]$} & {$[\mathrm{LS}]$} \\
\hline$[$ Plan 2] & {$[\mathrm{LS}]$} & & {$[\mathrm{LS}]$} & {$[$ Fracture Zone $]$} & & {$[\mathrm{LS}]$} & {$[\mathrm{LS}]$} \\
\hline$[$ Plan 3] & {$[\mathrm{LS}]$} & {$[\mathrm{LS}]$} & & {$[$ Fracture Zone $]$} & {$[\mathrm{LS}]$} & & {$[\mathrm{LS}]$} \\
\hline$[$ Plan 4] & {$[\mathrm{LS}]$} & & {$[\mathrm{LS}]$} & {$[$ Fracture Zone $]$} & {$[\mathrm{LS}]$} & & {$[\mathrm{LS}]$} \\
\hline
\end{tabular}

---LS :means the place to install Locking Screw

\section{Comparative Study and Mechanical Analysis}

\subsection{Boundary Conditions and Load}

According to femoral shaft stress described above, the simplified model is represented as Fig. 7. 


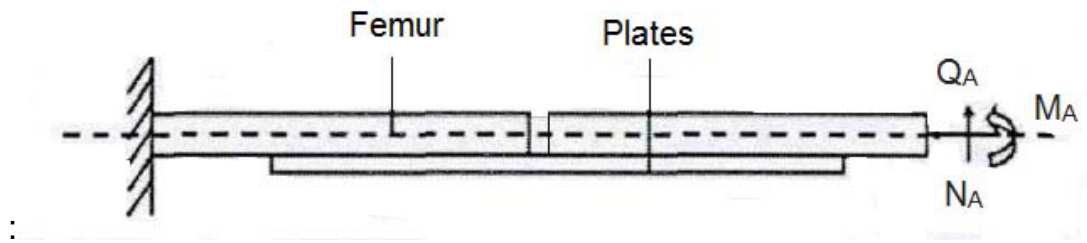

Fig. 7 The simplified model

Complicated model can be simplified as the cantilever model. That is, the boundary conditions for the plate fixation system are the distal end of femur should be fixed completely; and on which the vertical downward force NA $=709.5 \mathrm{~N}$, the force on parallel interface and away from the femur plate $\mathrm{QA}=143.1 \mathrm{~N}$; and torques $\mathrm{MA}=44800 \mathrm{Nmm}$. In accordance with $\mathrm{BO}$ principle of bridge principle, there is a gap of $3 \mathrm{~mm}$ between plate and femur.

The contact between the locking screw and plate and the contact between locking screw and femur are all set as "bonded" in ANSYS Workbench 14.0.

\subsection{Pre-treatment}

To mesh the femur models, and assembly model consisting of titanium plate and locking screw. All of plan are in the same method of mesh, and take plan 1 as an example as Fig. 8.

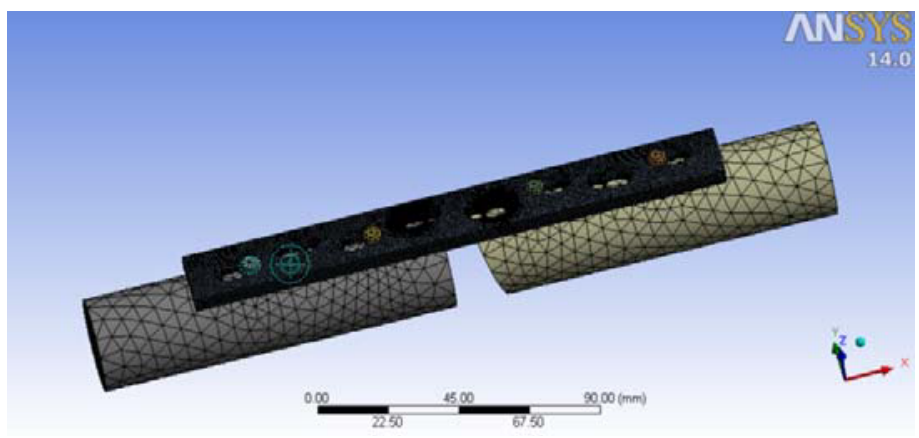

Fig. 8 The meshing model of plan 1

\subsection{Solution and Post-processing}

Through the above solution, the results will be summarized into the following Table 2: 
Table 2 The Optimization Results

\begin{tabular}{|c|c|c|c|c|}
\hline [Index of Evaluation] & [Plan 1] & [Plan 2] & [Plan 3] & [Plan 4] \\
\hline [Displacement of the proximal femur(mm)] & {$[6.82]$} & {$[5.88]$} & {$[5.554]$} & {$[4.516]$} \\
\hline [Maximum equivalent stress of plate(Mpa)] & [3204.1] & [2964.9] & [2722.3] & {$[1938.4]$} \\
\hline [Place of maximum equivalent stress of plate] & $\begin{array}{l}\text { [2th } \\
\text { hole] }\end{array}$ & $\begin{array}{l}{[2 \text { th }} \\
\text { hole }]\end{array}$ & $\begin{array}{l}{[3 \mathrm{rd}} \\
\text { hole }]\end{array}$ & $\begin{array}{l}{[3 \mathrm{rd}} \\
\text { hole }]\end{array}$ \\
\hline $\begin{array}{l}\text { [Maximum stress of plate in fracture } \\
\text { zone(Mpa)] }\end{array}$ & [1042.3] & [1066.9] & [1083.3] & {$[1084.4]$} \\
\hline $\begin{array}{l}\text { [Place of maximum stress of plate in fracture } \\
\text { zone] }\end{array}$ & $\begin{array}{l}{[4 \text { th }} \\
\text { hole }]\end{array}$ & $\begin{array}{l}{[4 \text { th }} \\
\text { hole }]\end{array}$ & [4th hole] & [4th hole] \\
\hline $\begin{array}{l}\text { [Maximum equivalent stress of the screw } \\
(\mathrm{Mpa})]\end{array}$ & [2595.7] & {$[2209.1]$} & [2118.3] & [1341] \\
\hline $\begin{array}{l}\text { [Place of maximum equivalent stress of the } \\
\text { screw] }\end{array}$ & [1st hole] & [1st hole] & {$[1$ st hole $]$} & [1st hole] \\
\hline [Maximum shear stress of the screw (Mpa)] & {$[350.72]$} & {$[298.13]$} & {$[277.38]$} & {$[154.14]$} \\
\hline [Place of maximum shear stress of the screw] & [1st hole] & [1st hole] & {$[1$ st hole $]$} & [1st hole] \\
\hline
\end{tabular}

\section{Conclusions}

It can be found that equivalent stress, screw shear stress and maximum stress in 1, 2, 3 are obviously more than the forth plan. And the maximum equivalent stress is at the joint of locking hole and pressurization hole, indicating greater stress focus here will cause destruction of locking screw holes; and locking screw stress concentration presents at the junction of screw shaft and screw head, it is also consistent with the actual situation. In summary, the forth is the best option, in order to design better plate system, some optimization for plate structure still need to be studied for the further.

\section{Acknowledgements}

This research is supported by the National Natural Science Funds of China (NSFC. 51375357) and the key education research project of Wuhan University of Technology (No.2013028). 


\section{References}

1. D. Kazuy, S. Kajihar, K. Morit, et al., The influence of fixation in formalin on the measurement of stability of implants using resonance frequency analysis and periotest M: A study in a dog, British Journal of Oral and Maxillofacial Surgery. 52 (2014) 29-33.

2. M. Ahmad, R. Nanda, A. S. Bajwa, et al., Biomechanical testing of the locking compression plate: when does the distance between bone and implant significantly reduce construct stability, Injury, 38 (2007) 358-364.

3. P. A. D. Jewell, S. Gheduzzib, M. S. Mitchell, et al., Locking plates increase the strength of dynamic hip screws, Injury, 39 (2008) 209-212.

4. D. G. Carolina, M. N. Andrew, M. Browne, Probabilistic finite element analysis of the uncemented hip replacement-effect of femur characteristics and implant design geometry, Journal of Biomechanics, 43 (2010) 512-520.

5. K. Akiyama, T. Sakai, N. Sugimoto, et al., Three-dimensional distribution of articular cartilage thickness in the elderly talus and calcaneus analyzing the subchondral bone plate density, Osteoarthritis and Cartiage, 20 (2012) 296-304. 